Proceedings of the 2010 Winter Simulation Conference

B. Johansson, S. Jain, J. Montoya-Torres, J. Hugan, and E. Yücesan, eds.

\title{
PROCESS SIMULATION ENVIRONMENT FOR CASE STUDIES
}

\author{
Jānis Grabis \\ Institute of Information Technology \\ Riga Technical University \\ Kalku 1 \\ Riga, LV-1658, LATVIA
}

\author{
Charu Chandra \\ College of Business \\ University of Michigan-Dearborn \\ 19000 Hubbard Drive \\ Dearborn, MI 48126, USA
}

\begin{abstract}
Using case studies helps learning and understanding complex issues in operations and supply chain management studies but preparing models for indepth exploration of case studies is time consuming and requires model-building skills. In order to address these issues, an environment for analyzing case studies is developed. The process-oriented approach is used as a basis for analyzing operations and supply chain management problems with emphasis on exploring relationships among different value chain processes such as manufacturing, logistics, marketing and finance. Process flow simulation is used to obtain quantitative process performance measures. Three main components of the environment are catalog of case studies, enterprise management dashboard and process modeling component. These components are implemented using commercially available spreadsheet and process modeling software. The environment can be used for implementation and exploration of different cases studies. Usage of the environment is demonstrated by analyzing a sample case study.
\end{abstract}

\section{INTRODUCTION}

Using case studies is a widely accepted approach to teaching operations and supply chain management. Case studies provide a concise description of often real-life supply chain management situations and trainees are requested to elaborate a plan of action suitable for the given situation. Exploration of the case studies mostly relies on qualitative and static problem assessment supported by some relatively simple quantitative calculations and modeling. However, many additional insights could be gained by extending quantitative analysis and exploring dynamic aspect of the case studies. That requires spending additional time on modeling and significant modeling skills. These requirements often are prohibitive if case studies are analyzed during short training sessions or trainees do not have quantitative modeling background.

A number of software tools have been elaborated to facilitate case analysis. The Beer game is one of the best known examples (Sparling 2002). Popularity of this game has been determined by simplicity of its usage and its power to demonstrate supply chain dynamics and importance of collaboration. Several tools attempting to cover wider range of issues in operations and supply chain management also have been developed. Shtub (2001) has developed the Operation Trainer, which covers purchasing, manufacturing and sales. This tool is also integrated with an Enterprise Resource Planning system which enables simulating the implementation of operational decisions. A learning tool for analysis of supply chain networks has been developed by Siddiqui, Khan and Akhtar (2008). The authors emphasize positive feedback received from students and instructors using the tool. Zhou et al. (2008) have elaborated a supply chain simulation game, which allows exploring such supply chain concepts as customer relationships management, capacity planning, quality control, transportation strategies and performance measurement. One feature of these tools is that they are developed for exploring particular case studies. 


\section{Grabis and Chandra}

The objective of this paper is to develop a modeling environment, which can be used for exploring different cases studies in the area of supply chain management. This environment is intended for in-depth analysis of problems described in case studies. It should provide mechanisms for relatively easy implementation of case studies and efficient and user-friendly facilities for conducting the exploration process. A process-oriented approach (Anupindi et al. 2006) is adopted for exploring supply chain management concepts. Therefore, the environment is referred as to Process Simulation Environment for Case Studies (PS4CS). The process-oriented approach allows gaining detailed insights in how value is created in companies and their supply chains and to trace dynamics of supply chain operations. Simulation is used to analyze process flow in complex and stochastic situations.

The distinctive features of PS4CS are implementation of multiple case studies, the process-oriented approach and focus on process improvement, and integration of different aspect of operations and supply chain management such as manufacturing, sales, finance and product development. PS4CS is developed on the basis of commercially available modeling tools that provide flexibility to go beyond its standard features and to develop fully-fledged models. Several case studies have been implemented using PS4CS. The Scharffen Berger Chocolate manufacturing case (Snow, Wheelwright and Wagonfeld 2007) is used as an example to describe PS4CS in this paper. The environment and the implemented case studies have been used in continuous education sessions for entrepreneurs at the University of Michigan-Dearborn.

The rest of the paper is organized as follows. Section 2 defines main requirements for PS4CS and discusses theoretical background used to develop the environment. Main components of PS4CS are discussed in Section 3. Implementation of PS4CS and its application in case study analysis are described in Section 4. Section 5 concludes.

\section{REQUIREMENTS AND THEORETICAL BACKGROUND}

Primary requirements for the environment are set by teaching objectives and characteristics of trainees. There are three main teaching objectives: 1) to offer an overview of supply chain management concepts; 2) to demonstrate how these concepts can be practically applied in improving supply chain performance; and 3) to illustrate relationships between supply chain management and other managerial disciplines such as finance, marketing and product development, i.e., to provide understanding of interconnectedness of managerial activities. Initially, the environment is developed for training a group of entrepreneurs. Members of this group have different backgrounds and represent several industries. They are results oriented focusing on business analysis rather than on technicalities process simulation

In order to elaborate these requirements, several well established concepts are adopted. The set of relevant supply chain management concepts is established using some well-known textbooks in operations and supply chain management and particularly using the book by Cachon and Terwiesch (2006). Process flow modeling techniques (Anupindi et al., 2006) are adopted to enable dynamic analysis and using process improvement principles in exploring case studies. Porter's values chain (Porter, 2004) is used as a framework for describing interactions between different process areas (Figure 1). High level activities defined as in the value chain are used as a starting point for further decomposition of supply chain activities. This representation focuses on the primary activities. The only secondary activities covered are product development and finance. The finance is not directly included in the process model but financial data are accumulated during modeling process and subsequently represented as part of the case study analysis. Customer demand and Research and development activities serve as two entry points of supply chain processes. The process representation shows only main links among the value chain activities while other interactions can be represented at the level of subprocesses. 


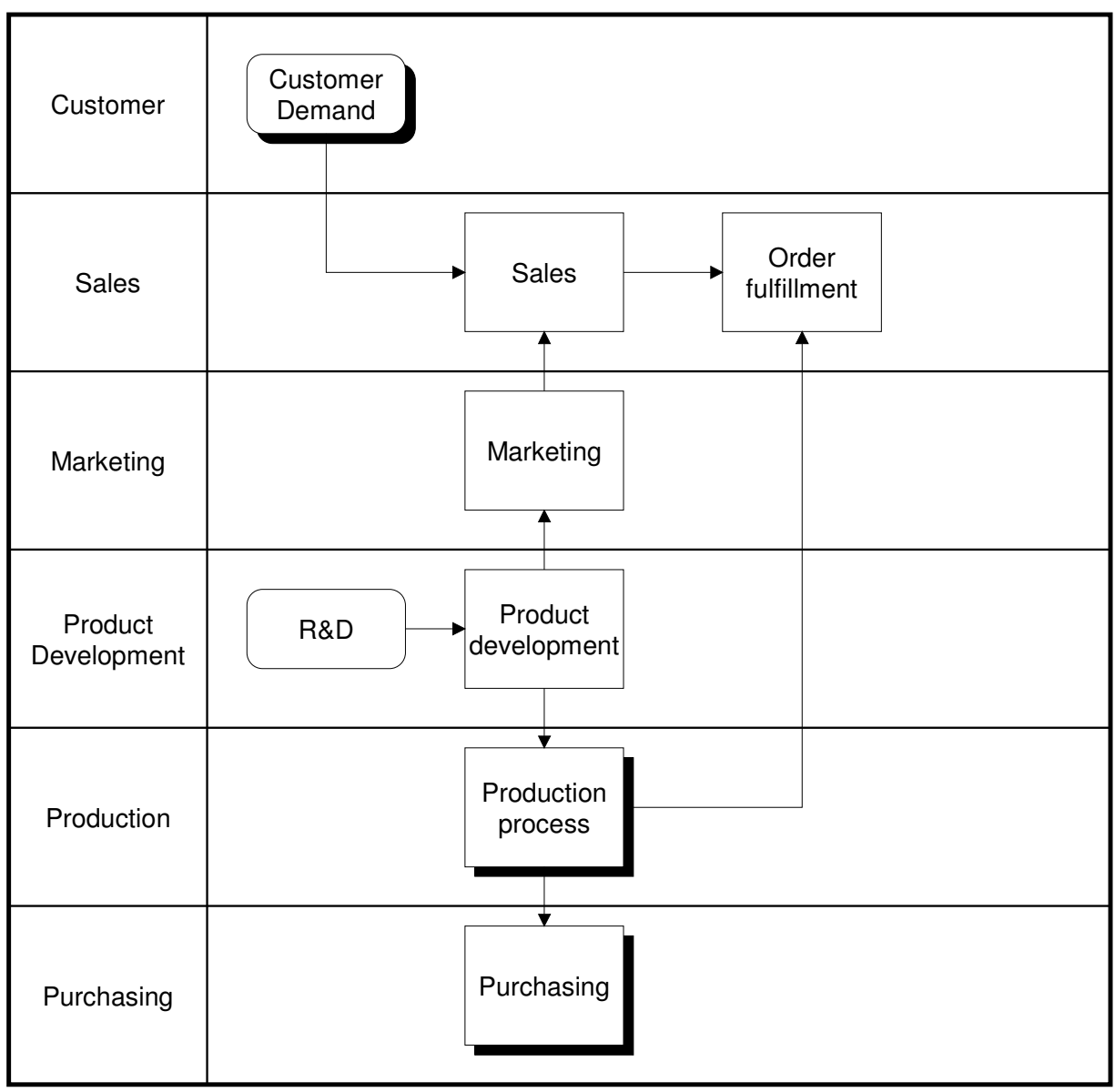

Figure 1: Process-oriented representation of value chain activities

Representation of different operations and supply chain management concepts depends upon choice of case studies to be implemented on the basis of the environment and to be used in training, though the primary set of concepts considered includes:

1. Representation of supply chains using process flow modeling and process life-cycle;

2. Basic flow measurements;

3. Capacity planning;

4. Impact of uncertainty and inventory management;

5. Outsourcing and distribution strategies;

6. Quality control and lean manufacturing.

PS4CS software obviously is required to provide means for exploring the aforementioned concepts which constitute the main set of functional requirements. Other more specific software requirements are:

1. Providing a rich fully functional process modeling environment;

2. Use of user-friendly techniques for data input/output operations (e.g., using spreadsheets);

3. Availability of key process performance measures;

4. Accounting for stochastic factors;

5. Simulation modeling capabilities;

6. Availability of different supply chain management policies;

7. Representation of financial implications of managerial decisions;

8. Representation of interactions between value chain activities. 


\section{Grabis and Chandra}

\section{COMPONENTS OF THE ENVIRONMENT}

The PS4CS environment has three main components: 1) Catalog of case studies; 2) Enterprise management dashboard; and 3) Process modeling component (Figure 2). Its main purpose is to provide users with a familiar and easy to use environment for studying supply chain management and entrepreneur skills by means of exploring business case studies. The environment allows users with minimal previous exposure to process modeling and analysis to master complex supply chain management concepts.

In order to satisfy requirements concerning data input/output using spreadsheets and process modeling and simulation, the COTS (commercial-of-the-shelf) software development approach has been selected. Microsoft Excel is used to implement the Enterprise Management Dashboard and iGrafx Process is used for process modeling purposes. Components of PS4CS are built on top of these commercial products, and both commercial products are integrated together. iGrafx Process primarily is process modeling and visualization software but it also provides process simulation capabilities.

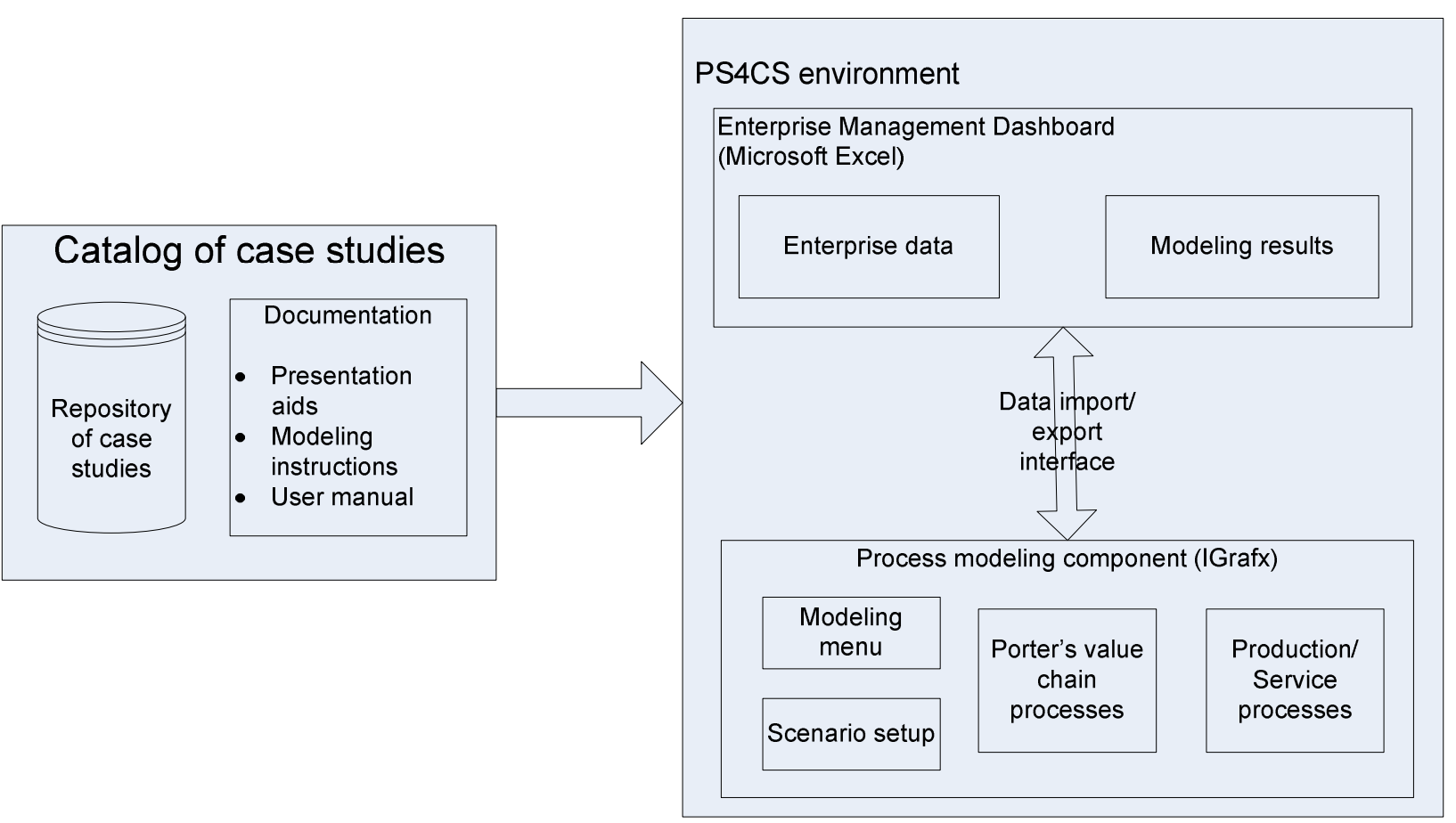

Figure 2: Components of PS4CS

\subsection{Catalog of Case Studies}

The Catalog of case studies serves as a starting point for using the PS4CS environment. That includes implemented case studies, documentation and training aids (e.g., description of cases studies subject to legal requirements, presentation slides). Implemented case studies are stored in the Repository of case studies. Each case study has enterprise data definition file and process modeling diagrams.

\subsection{Enterprise Management Dashboard}

The purpose of the Enterprise management dashboard is to provide input data for process modeling, support static analysis of case studies and to represent process simulation results. The Enterprise management dashboard has the following modules (the modules correspond to value chain activities of the Porter's value chain): 


\section{Grabis and Chandra}

- Product - the module allows adding new products and editing product information. Product development related data such as development cost and product bill-of-materials are also managed using this module;

- Resource - the module allows adding new resources, editing resource information and representation of resource usage policies and investment decisions. Resource requirements for each product are also indicated;

- Sales - the module maintains information about expected and actual customer demand. Different demand patterns can be represented and different demand forecasting methods can be used ;

- Purchasing - the module maintains information about components used in manufacturing products and about inventory management policies;

- Finance - the module provides summary of financial performance measures calculated according to either static or dynamic analysis of enterprise data. Revenues and expenses breakdown by month is also provided to support cash flow analysis;

- Marketing - the module provides data on marketing activities aimed at increasing sales and reducing demand uncertainty.

It is important to note that some of data included in the Enterprise modeling dashboard also can be edited using the Process modeling component. However, such data as investment cost, product development costs and marketing activities can only be defined using the Enterprise modeling dashboard. This way users can choose the most convenient data editing mode as well as operate with enterprise data usually not represented in process models.

Additionally, the Enterprise management dashboard has a module for representing modeling results. This module represents modeling results received from the Process modeling component, and these results are combined together with data specified only in the Enterprise management dashboard (e.g., investment data). Detailed results are stored for each individual business scenario explored during the case studies. The results summary table is used for the comparison of multiple scenarios according to key performance indicators.

\subsection{Process Modeling Component}

The purpose of Process modeling component is dynamic analysis of supply chain processes using simulation. The component is based on a commercially available process modeling software. The supply chain processes are represented according to the Porter's value chain processes and are hierarchically structured. The high level activities represent sales, purchasing, product development, marketing and production processes. Each higher level activity can be further decomposed to represent particular activities in more details. Decomposition is generally performed for production and purchasing processes.

The process modeling component receives input and management policies data from the Enterprise management dashboard; simulation is performed using built-in capabilities of the process modeling software and modeling results are transferred back to the Enterprise management dashboard. These functions are invoked using the Modeling menu. Additionally, there is also a Scenario setup component, which is used for managing specific scenarios of case analysis. It is aimed at streamlining modeling activities and is developed for each particular case.

\section{IMPLEMENTATION}

PS4CS is implemented according to the aforementioned requirements and the architecture described in Section 3. The implementation has two main parts: 1) implementation of the PS4CS environment; and 2) implementation of case studies. The Sharffen Berger Chocolate maker case study (Snow, Wheelwright and Wagonfeld 2007) is used to illustrate implementation and usage of PS4CS. Currently, four other case 


\section{Grabis and Chandra}

studies also have been implemented (shoes manufacturing case, computer distribution case, scooter manufacturing case and hospital emergency treatment case). These cases have been implemented using data and scenarios described in published data sources, Custom cases studies can be developed by PS4CS's users.

\subsection{Sample Case Study}

The Scharffen Berger is a high-end premium chocolate manufacturer, wholesaler and retailer located in Berkeley, California. Demand has always exceeded capacity and it could be tripled over the next five years. The company is looking for ways to increase capacity while ensuring the quality of their products. The teaching objectives of this case are capacity planning through bottleneck identification and elimination as well as understanding of relationships between process and product quality. Additionally, the original case has been expanded to investigate outsourcing in relation to capacity planning and quality. Several modeling scenarios are identified what are explored using PS4CS. These scenarios are:

1. Demand increase in the As-Is situation (before any changes are made in the process);

2. Redesign from the As-Is process to the To-Be process;

3. Demand increase in the To-Be situation (after process redesign);

4. Process balancing;

5. Inventory management in the case of demand variability;

6. Core competencies and outsourcing;

7. Quality problems.

The scenarios use process modeling capabilities to explore different aspects of process improvement and dynamic analysis beyond that originally considered in the Scharffen Berger case.

\subsection{Software Implementation}

The Catalog of cases studies is implemented as a simple database containing case descriptions and references to workbooks containing enterprise data and to iGrafx diagrams containing process models. Users use the catalog to access the case study they need.

The Enterprise Management Dashboard is implemented using Microsoft Excel (Figure 3). It provides both data input and output functionality. The main commands menu (denoted by 1 in Figure 3 ) is used to control user interactions with PS4CS. It contains commands for accessing modules representing the value chain processes. The main command menu is also used to invoke functions for displaying modeling results (2) received from iGrafx (see Section 4.3). The PS4CS desktop (3) is used to specify enterprise data as well as to display modeling results. Data input forms (4) are provided to facilitate data input operations.

The Process Modeling component is implemented using iGrafx Process, which is modified to include additional features for easier manipulation of scenario data and for interaction with the Enterprise Management Dashboard component. User interactions with the Process Modeling component are controlled using the Main process modeling menu and the Scenario menu (referred using 1 and 2 in Figure 4, respectively). The main process modeling menu contains commands for interfacing with the Enterprise management dashboard including import of scenario settings and transfer of modeling results back to the Enterprise management dashboard. This menu and its functionality is shared by all case studies. The Scenario setup menu is specific to a particular cases study and contains functions for setting up parameters of scenarios considered during exploration of the case study. For the Scharffen Berger case, the Scenario setup menu allows changing demand, adding new resources, adding multiple shifts, changing level of outsourcing and adjusting inventory management policies. Figure 4 also shows the project explorer containing all processes and subprocesses and a sample of one of the subprocesses. 


\section{Grabis and Chandra}

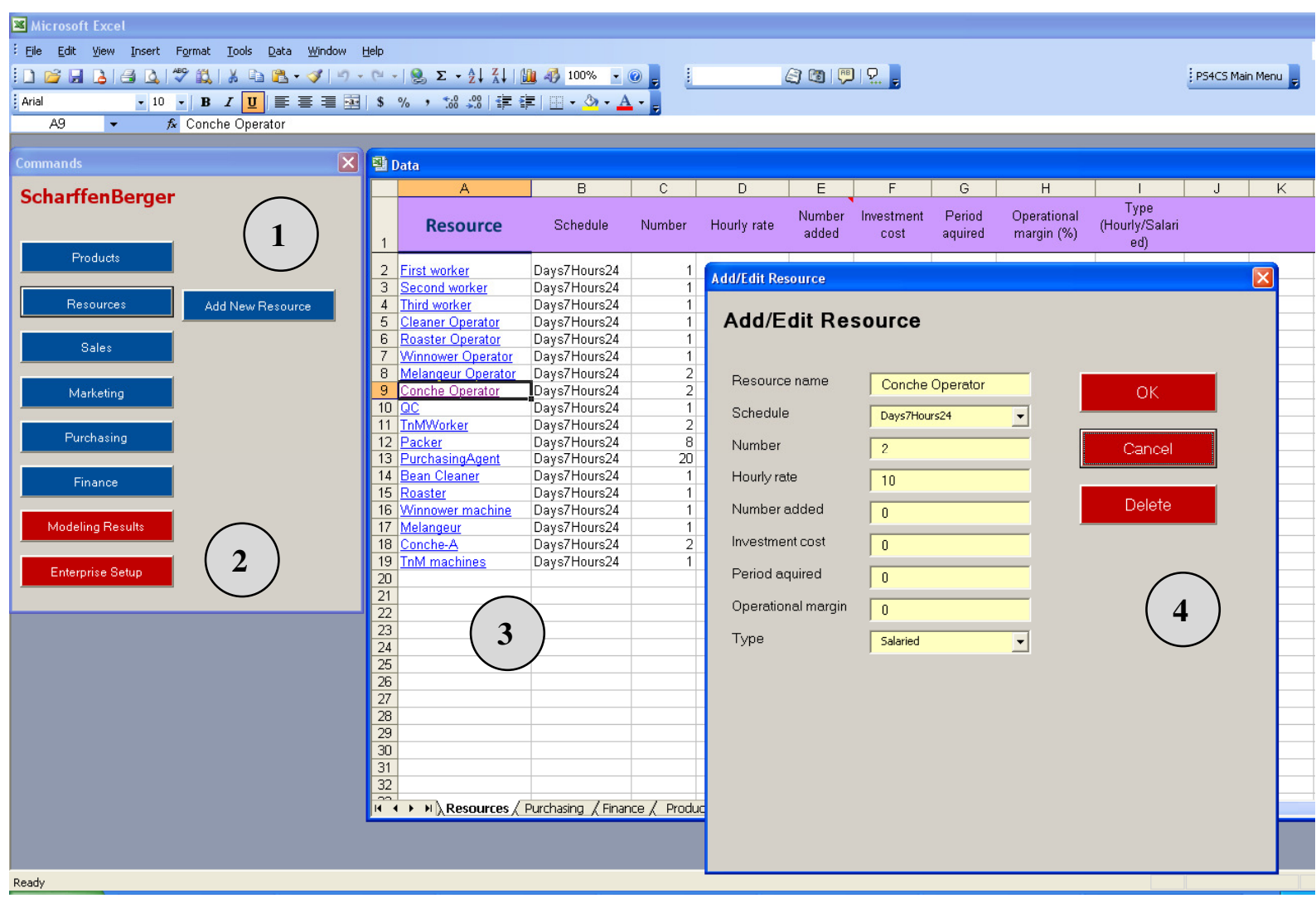

Figure 3: Enterprise management dashboard

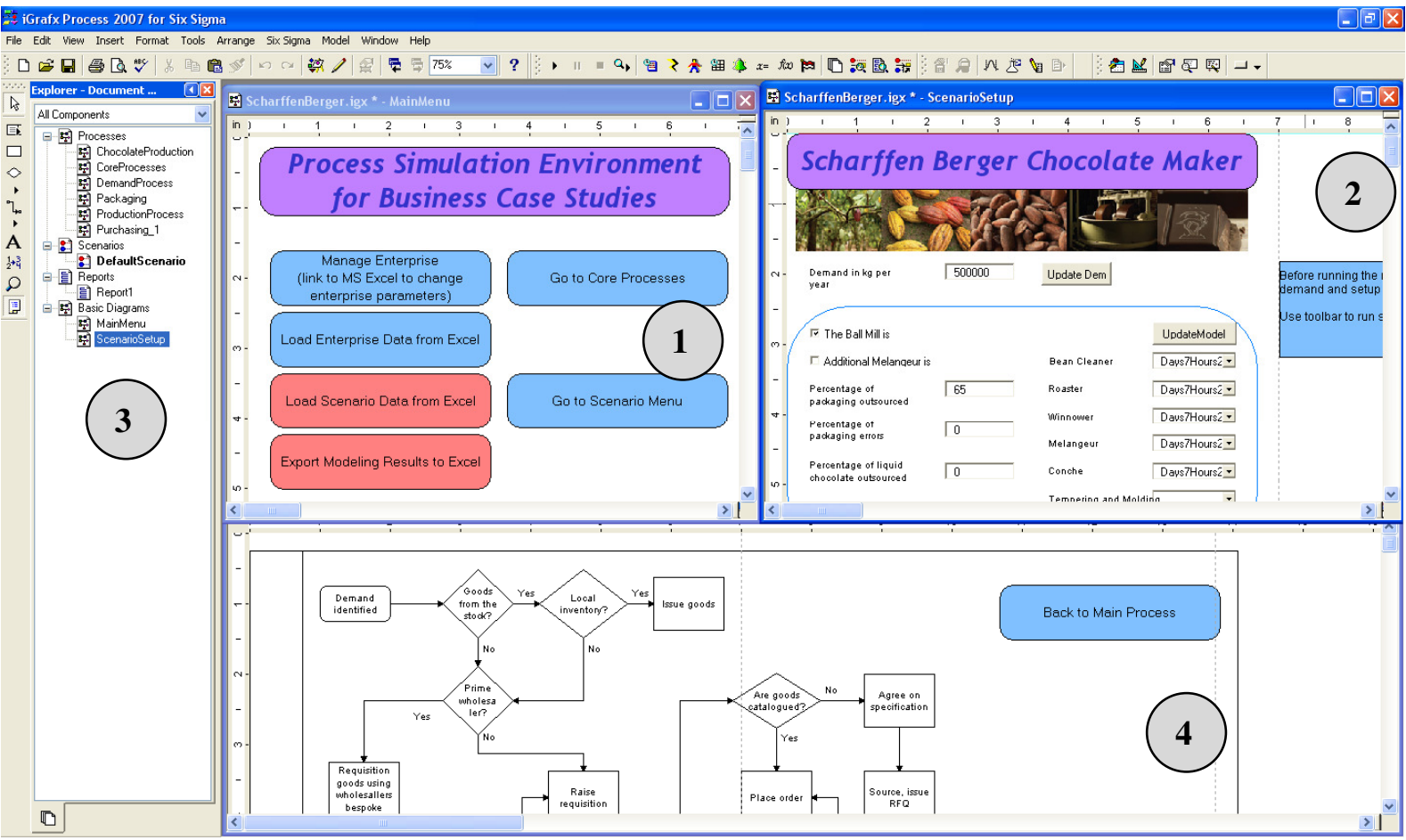

Figure 4: Process modeling environment 


\section{Grabis and Chandra}

Integration between the Enterprise Management Dashboard and the Process Modeling component is implemented using iGrafx Process and Microsoft Excel application programming interfaces. Modeling setup data and modeling results are transferred from one application to another in the batch mode while product, resource and other characteristics not stored in iGrafx are accessed directly from Microsoft Excel by the Process Modeling Component.

\subsection{Case Study Exploration}

In order to show results obtained using PS4CS, modeling results obtained using process simulation for Scenarios 1 and 3 are presented. Scenario 1 investigates ability of the Scharffen Berger Chocolate maker to meet customer demand without redesigning the manufacturing process (referred to as the As-Is situation). Therefore, the main process performance measures process throughput, flow time and inventory size are determined for different levels of customer demand. The customer demand levels considered are $330,000 \mathrm{~kg} /$ years, 500,000 kg/years and 750,000 kg/years. Scenario 3 investigates ability of the Scharffen Berger chocolate maker to meet customer demand after installing additional equipment at the bottleneck activity and balancing the production process (a ball mill is installed to reduce time of conching, which was the bottleneck in Scenario 1). Scenario 3 is referred to as the To-Be situation. Figure 5 compares the ability to meet the growing customer demand for Scenarios 1 and 3. It can be observed that the manufacturing process is not capable of producing more than $500,000 \mathrm{~kg} / \mathrm{year}$ and excess demand cannot be met in the case of As-Is situation. The flow time increases exponentially because manufacturing orders are generated with regard to the increasing demand and the process gets clogged with semi-processed chocolate. In the case of To-Be situation, the process is able to cope with the increasing demand. A slight increase in flow time can be observed suggesting that queuing starts to occur at high levels of demand and further demand increases could be difficult to accommodate. PS4CS has been used to identify and check further necessary process improvements. The obtained results show that throughput can be increased up to $1,250,000 \mathrm{~kg} / \mathrm{year}$ by adding new equipment, increasing number of shifts and the proportion of outsourcing.
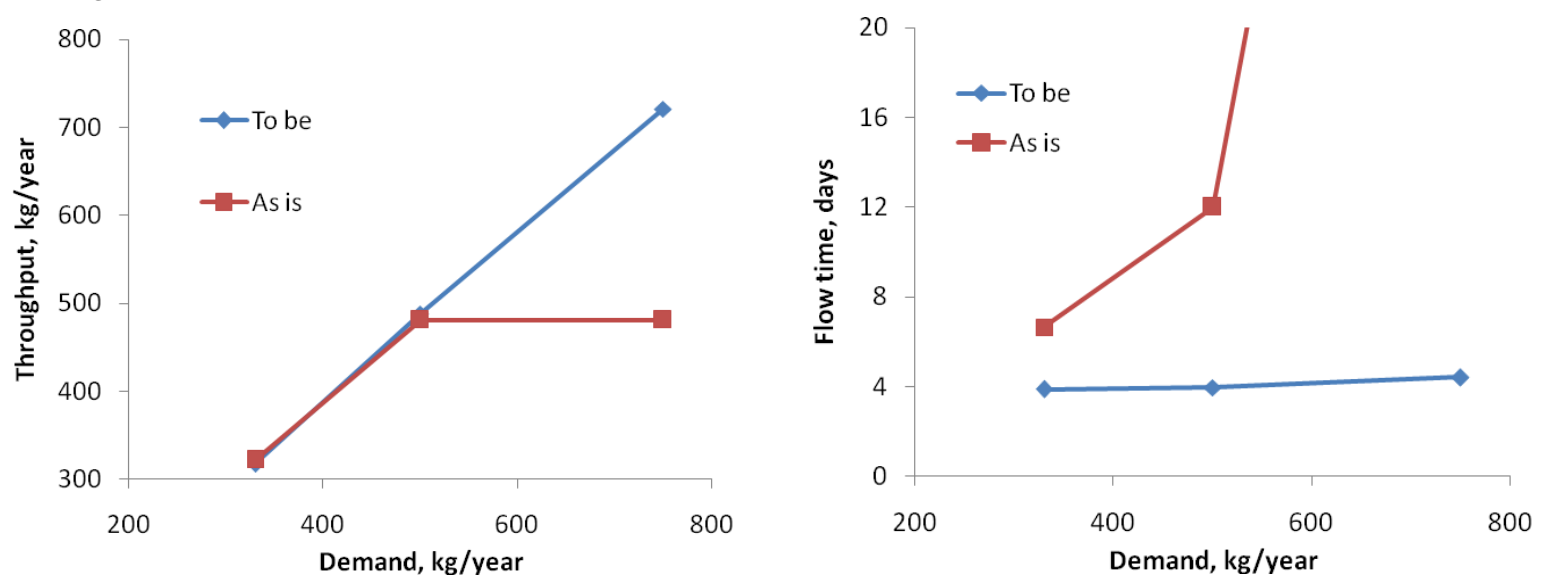

Figure 5: Systems throughput and flow time according to demand

An important feature of PS4CS is the integration between different value chain processes and possibilities to evaluate financial performance according to modeling results. Figure 6 shows the total revenues/costs calculation and its monthly breakdown as well as the summary of obtained experimental results. The financial analysis combines enterprise input data and modeling results to evaluate financial implications of decisions made. The summary of experimental results allows comparing the most important performance measures for different scenarios investigated during exploration of the case study. 


\section{Grabis and Chandra}

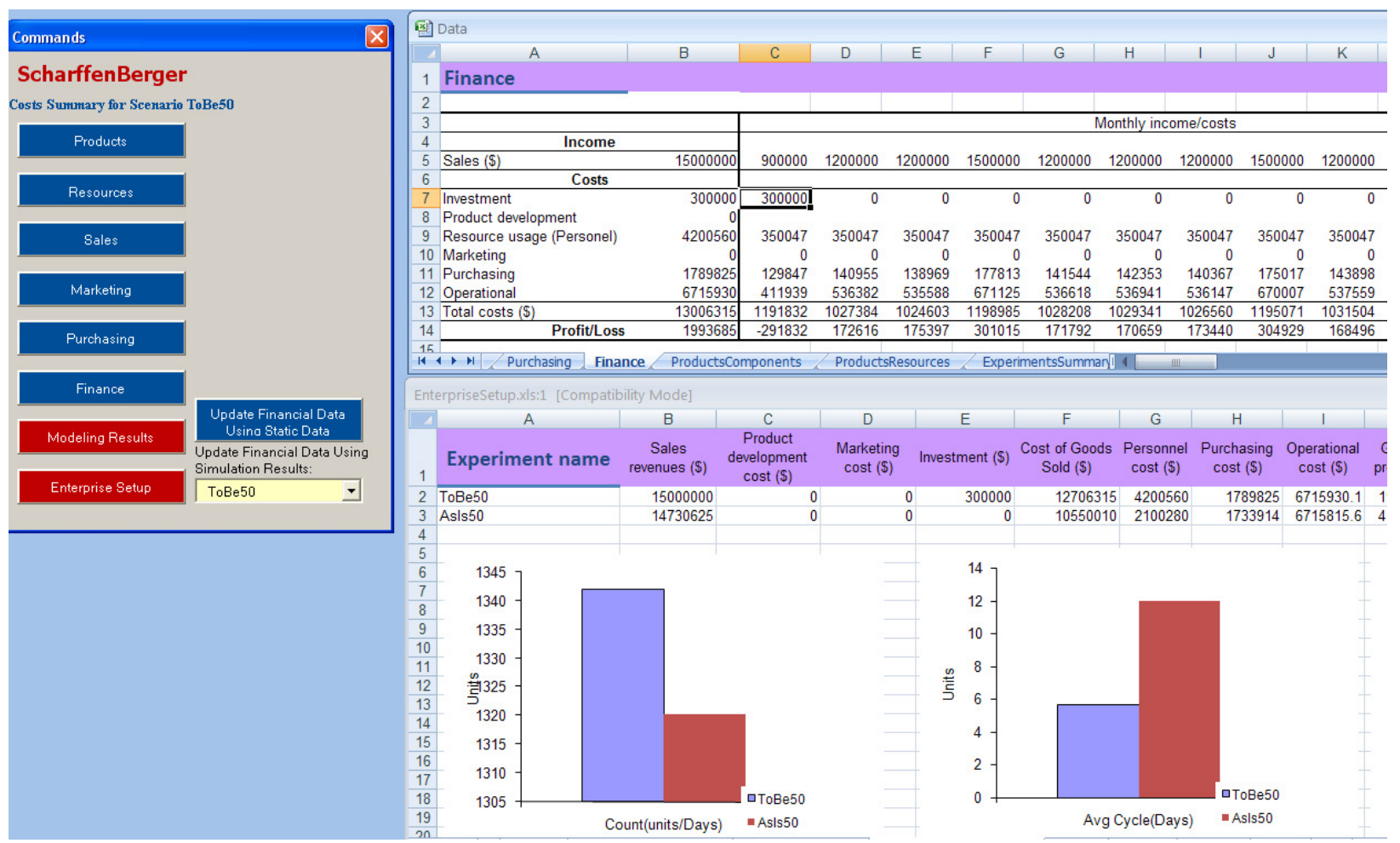

Figure 6: Representation of modeling results

\section{CONCLUSION}

The environment for exploring case studies used in teaching operations and supply chain management has been developed. It uses process modeling and simulation for in-depth analysis of case studies. Several case studies including the Scharffen Berger Chocolate maker case discussed in the paper have been implemented using PS4SC. PS4SC and the implemented case studies have been successfully used in several training sessions for continuous education of entrepreneurs, which has allowed raising process awareness of trainees and to illustrate relationships between process improvement and quantitative analysis tools available in operations and supply chain management.

A limitation of using PS4SC is that trainees would not comprehend complexities of model development and would not understand all assumptions made for modeling purposes. Therefore, the trainees should be made fully aware that they act as consumers of ready-to-use models and that model building and validation require extra effort in practical situations. PS4CS is designed to require trainees only limited knowledge of iGrafx process modeling environment. Other process modeling tools with simulation capabilities and available application programming interfaces could be used instead of iGrafx. However, that would require some redevelopment efforts.

PS4SC can take full advantage of standard capabilities of commercial tools used in its implementation. For instance, the iGrafx process modeling software provides functions for analysis of quality related issues using cause-and-effect diagrams as well as integration with Minitab for statistical quality control.

\section{REFERENCES}

Anupindi, R., S. Chopra, S.D. Deshmukh, J.A. Van Mieghem, and E. Zemel. 2006. Managging Business Process Flows Principles of Operations Management. Pearson Prentice Hall, Upper Saddle River.

Cachon, G., and C. Terwiesch. 2006. Matching Supply with Demand: An Introduction to Operations Management. McGraw-Hill Irwin, New York. 


\section{Grabis and Chandra}

Stevenson, M., Y. Huang and L. C. Hendry. 2009. The development and application of an interactive enduser training tool: part of an implementation strategy for workload control, Production Planning \& Control: The Management of Operations 20:622 - 635.

Snow, D. C., S. C. Wheelwright, and Alison Berkley Wagonfeld. 2007. Scharffen Berger Chocolate Maker. Harvard Business School Case 606-043.

Porter, M. 2004. Competitive Advantage. Free Press.

Siddiqui, A., M. Khan, and S. Akhtar. 2008. Supply chain simulator: A scenario-based educational tool to enhance student learning. Computers \& Education. 51:252-261.

Shtub, A. 2001. A framework for teaching and training in the Enterprise Resource Planning (ERP) era. International Journal of Production Research. 39:567-576.

Sparling, D. 2002. Simulations and supply chains: Strategies for teaching supply chain management. Supply Chain Management. 7:334-342

Zhou, L., Y. Xie, N. Wild and C. Hunt. 2008. Learning and practicing supply chain management strategies from a business simulation game: a comprehensive supply chain simulation. In Proceedings of the 2008 Winter Simulation Conference, S. J. Mason, R. R. Hill, L. Mönch, O. Rose, T. Jefferson, J. W. Fowler (eds.), 2534-2542.

\section{AUTHOR BIOGRAPHIES}

JĀNIS GRABIS is a Professor at the Faculty of Computer Science and Information Technology, Riga Technical University, Latvia. He obtained his PhD from the Riga Technical University in 2001 and worked as a ResearchAssociate at the College of Engineering and Computer Science, University of Michigan-Dearborn. He has published in major academic journals including OMEGA, European Journal of Operational Management, International Journal of Production Research, Human Systems Management and others. He has been a guest-editor for two top academic journals and member of the program committee of several academic conferences. His research interests are in supply chain management, enterprise applications and project management. His email address is grabis@iti.rtu. Iv $>$.

CHARU CHANDRA is a Professor of Operations Management at the College of Business, University of Michigan-Dearborn. Prior to this appointment, he was a Professor of Industrial and Manufacturing Systems Engineering in the College of Engineering and Computer Science. His Ph.D. and Masters degrees are in industrial engineering and operations research from the Arizona State University, Tempe and the University of Minnesota, Minneapolis, respectively. He also has a MBA degree. He is involved in research in supply chain management, and enterprise integration issues in large complex systems. He has published several books, papers in leading archival research journals, book chapters and conference proceedings in the areas of supply chain management, enterprise modeling, information systems support, inventory management, and group technology. He has also Guest Edited several journal issues on many of the above topics. He is the Area Editor of OMEGA and serves on the Editorial Board of several academic journals with editorial responsibilities for supply chain management, enterprise engineering, and health systems management track papers. He is actively involved in several academic and professional societies in various capacities. His e-mail address is <charu@umich.edu>. 